\title{
A Questão Institucional e suas Implicações para o PensamentoEstratégico
}

\author{
João Marcelo Crubellate \\ Paulo Sérgio Grave \\ Ariston Azevedo Mendes
}

\section{RESUMO}

Tradicionalmente a perspectiva estratégica e a perspectiva da teoria institucional em organizações vêm sendo entendidas como abordagens incomunicáveis e até excludentes. Mais recentemente, contudo, uma série de novos estudos parte da teoria institucional para tentar entender fenômenos vinculados ao pensamento estratégico em organizações. Tal tentativa de conciliar padrões institucionais e agência estratégica, que se torna crescentemente aceita no âmbito da teoria organizacional, parece ainda não ter obtido ressonância no âmbito dos estudos específicos de estratégia organizacional. Nesse sentido é que o presente artigo busca oferecer sua principal contribuição. Os objetivos centrais aqui foram propor sistematização das várias vertentes da teoria institucional em organizações, utilizando-se artigos acadêmicos geralmente considerados essenciais para o seu entendimento, e sugerir as possíveis contribuições dessas vertentes para a explicação ou re-explicação do pensamento estratégico. Pode-se concluir que a análise organizacional se beneficia do esforço de conjugação daquelas duas perspectivas analíticas, bem como de cada uma delas separadamente, em vários aspectos.

Palavras-chaves: estratégia; neo-institucionalismo; ambiente institucional; ação.

\begin{abstract}
The analysis of strategy in organizations and the institutional theory have been developed, until recently, as incompatible approaches to decision and action. However a set of new organizational researches based on institutional theory are trying to conciliate the idea of strategic agency and the influence of institutional patterns to explain how decisions are taken and how organizations connect to their environments. As the field of strategy research has not yet seriously taken that possibility, with some few but relevant exceptions, it seems that new contributions are required. So, the main purposes of this paper were: to summary institutional theory perspectives in organization academic field and to suggest new theoretical and conceptual insights for the strategy theory from an institutional point of view. It is possible to conclude that the effort to conciliate those theoretical streams - strategy in organizations and institutional theory - is useful to organization theory, as much as to overcome some difficult aspects of strategic and institutional phenomena.
\end{abstract}

Key words: strategy; new institutionalism; institutional environment; action. 


\section{INTRODUÇÃo}

A estratégia organizacional é comumente pensada como fruto da racionalidade e da intencionalidade de decisores organizacionais (Andrews, 1981; Ackoff, 1983), sendo, então, tradicionalmente explicada com base em teorias fundamentadas no pressuposto de adaptação racional da organização a conjuntos externos e objetivos de condições ambientais. Essa visão tradicional é, por vezes e ultimamente com crescente ênfase, confrontada por perspectivas menos voluntaristas sobre a natureza do pensamento estratégico, que buscam entendêlo como desenvolvimento de processos mais ou menos involuntários de cognição, de relacionamento cultural, de negociação política ou mesmo de respostas pouco padronizadas em relação às contingências imediatas de uma realidade complexa e mutável.

Mintzberg, Ahlstrand e Lampel (2000) resumem várias dessas perspectivas. Curiosamente, uma das abordagens mais evidentes em voga na teoria organizacional, a teoria institucional, não recebe foco específico naquele trabalho. De fato, a perspectiva institucional coincide com essa confrontação presente na teorização sobre o processo estratégico, isto é, a contraposição entre a idéia de escolha racional e modelos alternativos de explicação da decisão e da ação, baseados em concepções menos estritas e que dão margem à análise de outros fatores, além da racionalidade (ou, como destacam Fonseca e Machado-da-Silva [2001], racionalidade do tipo instrumental), como elementos também importantes na tomada de decisão. Neste sentido é que a perspectiva institucional parece oferecer a possibilidade de identificação de interessantes insights para a compreensão de aspectos do pensamento estratégico.

Entretanto o fato de serem ainda relativamente poucas as tentativas de conciliação entre a teoria institucional e o pensamento estratégico parece estar vinculado não somente à tradição racionalista dos estudos em estratégia, mas também à visão mais correntemente difundida do institucionalismo em teoria organizacional, que preconiza a natureza taken for granted dos processos institucionalizados e, portanto, a conseqüente passividade das organizações em face de seus ambientes institucionais (Oliver, 1991).

Esses pressupostos que, como aqui se buscará demonstrar, correspondem hoje apenas a uma das várias vertentes possíveis do institucionalismo, deixavam quase naturalmente de fora da análise organizacional institucionalista a exploração dos fenômenos vinculados à agência estratégica das pessoas e dos sistemas sociais 
em que elas estavam envolvidas, interpretando de modo generalizado tais fenômenos apenas como expressão da ideologia gerencialista e voluntarista em administração e em teoria organizacional. Ao corrigir aqueles extremos, a teoria institucional deixava sem espaço uma série de perspectivas estratégicas de natureza mais analítica e menos prescritiva. Uma reaproximação entre os fenômenos de institucionalização e configuração estratégica, que era quase impensável sob aqueles dois extremos, passa a constituir-se em realidade a partir de estudos mais recentes da teoria institucional em organizações, fazendo emergir novas possibilidades de entendimento do fenômeno da elaboração de estratégias organizacionais, ainda pouco exploradas no âmbito da literatura especificamente estratégica.

Este artigo tem, portanto, como objetivos principais propor sistematização das várias vertentes da teoria institucional em organizações e sugerir as possíveis contribuições que se podem extrair dessas vertentes para a explicação ou reexplicação do pensamento estratégico. Na perspectiva da teoria institucional o pensamento estratégico passa a ser entendido como produto da imersão social dos agentes organizacionais, isto é, como sendo condicionado ou pelo menos influenciado por padrões coercitivos, normativos e cognitivos predominantes no contexto ambiental das organizações.

Por outro lado, nem todas as vertentes institucionalistas abandonam definitiva e completamente o pressuposto de escolha ou de adaptação racional como elemento relevante (ainda que não único) de explicação das opções de agentes individuais e das próprias organizações ${ }^{(1)}$. A conjugação de explicações de cunho subjetivista com explicações mais racionalistas parece ser uma das importantes tendências atuais na teoria das organizações (Scott, 2001; Weick, 2001). Já na literatura estratégica parece ainda predominar os pressupostos racionalistas, no máximo com a sugestão de suas limitações. Isto revela a importância de se desenvolverem explorações conceituais e empíricas relativas a outros elementos envolvidos no processo estratégico.

A superação da dicotomia instituição-agência estratégica não é importante apenas para o fortalecimento do poder explicativo da teoria institucional. Ela é também - e talvez de modo mais evidente - importante para a melhor compreensão do fenômeno da estratégia em organizações, nesse caso com implicações concretas para a prática administrativa que ainda estão por serem exploradas, para além do esforço de exploração e revisão teórica ao qual se limita este artigo. 


\section{Estratégia em Organizações: Escolha Racional e Modelos Alternativos de Explicação da Ação Organizacional}

A noção de formulação estratégica é comumente entendida como referindo-se à decisão por cursos de ação e, como tal, traz implícita a discussão relativa à natureza da realidade circundante das organizações e das formas de relação entre organizações e seus ambientes.

As perspectivas mais tradicionais estão relacionadas à idéia de ação racionalinstrumental, principalmente nas abordagens econômicas de organização, que supõem a busca intencional por eficiência como o parâmetro normal de toda a estratégia organizacional (ver, por exemplo, a descrição das escolas do design, de planejamento e de posicionamento feita por Mintzberg, Ahlstrand e Lampel [2000]). Subjacente a tais perspectivas encontra-se a visão objetivista da realidade: o ambiente organizacional tende a ser concebido como conjunto objetivo e unívoco de forças e demandas, que exigem resposta apropriada dos agentes no intuito de posicionar a organização de modo que ela sobreviva a tais pressões e, na medida do possível, as reverta, transformando-as em vantagens perante a outros concorrentes. A velocidade das respostas e a sua precisão (acoplagem) em relação às demandas contextuais são entendidas como os fatores determinantes do sucesso na formulação estratégica.

Assim, mediante esses pressupostos básicos, a formulação estratégica corresponderia a um modelo de escolha racional que pressupõe "um processo passo-a-passo que é tanto lógico quanto linear” (Miller, Hickson e Wilson, 1996, p.294). Nessa perspectiva, estratégia e planejamento são sinônimos. Nos termos de Whipp (1996, p.265) "em sua primeira manifestação o estudo da estratégia era inerentemente racional e não negava seu determinismo econômico [...]. O objetivo essencial era acessar o ambiente da empresa, projetar o futuro do negócio e ajustar estruturas e recursos internos em conformidade com aqueles fatores”.

Foram necessárias rupturas no âmbito da sociologia, da teoria organizacional e de outras ciências relacionadas, para que o pressuposto da escolha racional em estratégia começasse a ser questionado, o que só veio a ocorrer muito tempo depois que teorias de contraposição ou flexibilização dessa forma de racionalismo já se haviam estabelecido em outras áreas de estudo. Na teoria sobre o processo decisório, por exemplo, Simon (1970) desenvolveu o modelo segundo o qual limitações cognitivas dos decisores e também limitações na quantidade e na qualidade das informações disponíveis somente permitiam decisões "racionalmente limitadas". Lindblon (1959), por sua vez, defendeu que planejamento e ação eram dependentes, em grande medida, do acaso e de outros 
fatores não sujeitos ao planejamento e previsão racional. Na teoria organizacional, Weick (1969), com grande antecipação em relação aos estudos de estratégia, propôs que o ato de planejar estava mais vinculado à organização da realidade e da experiência passada dos decisores que à antecipação do futuro. Nos seus termos, "planos parecem existir em contexto de justificação mais do que em contexto de antecipação” (Weick, 1969, p.102).

No âmbito do pensamento estratégico, o pressuposto racionalista de realidade e ação passa a receber contraposição principalmente com as rupturas paradigmáticas levadas adiante na teoria organizacional, mais do que com críticas originadas na própria área de estratégia. Como afirmam Machado-da-Silva, Fonseca e Fernandes (1999, p.104), "observa-se que, desde o surgimento do modelo de sistema aberto, a formulação da estratégia passou a ser considerada como tarefa que envolve, mais do que o princípio da ação racional, a maneira como uma organização responde às demandas do ambiente. Logo, estratégia tornou-se um conceito que inclui tanto escolha como adaptação ambiental”. Com o movimento de questionamento da primazia do racionalismo como preceito único na decisão e ação organizacional, perspectivas alternativas de entendimento da formulação estratégica passaram a ser desenvolvidas a partir de diferentes pressupostos quanto à realidade (o ambiente circundante das organizações e dos tomadores de decisão) e quanto às formas pelas quais se dá o relacionamento entre organização e ambiente.

Retornando a Weick (1969), vê-se que o ambiente organizacional é definido, na sua perspectiva, como ambiente decretado ou ordenado ou ainda representado, algo mais do que simples resposta a forças objetivas, e também mais do que apenas a percepção e a interpretação subjetivas de padrões objetivos: o ambiente é socialmente construído. Como ele afirma, "ao invés de se adaptar a ambientes prontos, é inteiramente possível que os próprios atores criem o ambiente ao qual eles se adaptarão" (Weick, 1969, p.27). Temos aqui, portanto, uma noção construtivista de ambiente ou realidade, bem como uma proposta fenomenológica, como a define Scott (1992), sobre a relação entre os sistemas organizacionais e seu contexto ambiental. Ao contrário da busca por respostas racionais e diretas a demandas objetivas, tal relação passa a ser vista como processo subjetivo ou intersubjetivo de definição das características e das variáveis ambientais com que se confronta, resultando em ações, cuja lógica nem sempre, ou quase nunca, preenche todos os requisitos do modelo racional, uma vez que é essencialmente dependente de aspectos cognitivos dos indivíduos e grupos responsáveis pelas decisões.

Uma das conseqüências dessa forma de compreender a relação entre organizações e seu ambiente é que se passa a admitir a possibilidade de que, de 
fato, haja apenas a possibilidade de "acoplamento frouxo" ou frágil entre intenções e planos e as ações dos agentes organizacionais (Weick, 1976), porquanto tais ações são baseadas em significados individuais ou compartilhados pelos agentes organizacionais em relação a seu contexto e não apenas nas premissas racionalizadas que embasam os planos formais e que sugerem estreita relação entre intenções e ação. Aliás, também resulta dessa perspectiva fenomenológica a possibilidade de que a relação entre plano e ação seja invertida: a estratégia, nesse sentido, poderia até ser entendida como esforço de justificação de ações já desencadeadas, ao invés de receita racional para a ação (Weick, 1969).

Essa e outras perspectivas de natureza cognitiva, cultural ou política passam a confrontar a idéia de planejamento racional como único meio de elaboração estratégica nas organizações. No Brasil, mais recentemente, alguns estudos vêm sendo desenvolvidos em torno de algumas daquelas possibilidades anteriormente traçadas. Por exemplo, Vasconcelos (2002) elaborou proposta de abordagem de natureza construtivista, com foco no institucionalismo organizacional como recurso teórico, para a exploração das estratégias de organizações com atuação na Internet. Da mesma forma, Machado-da-Silva e Fonseca (1999) e Machadoda-Silva, Fonseca e Fernandes (1999) realizaram resgate sintético do debate entre as perspectivas de estratégia organizacional e fizeram sugestões para a sua compreensão a partir da teoria cognitiva e institucional. Tal elaboração tem seqüência com o artigo de Fonseca e Machado-da-Silva (2001), que busca analisar o conceito de estratégia sob as perspectivas da escolha estratégica, cognitiva e institucional de análise das organizações.

No âmbito de uma continuidade desse esforço nacional pela exploração de novas perspectivas de compreensão do fenômeno da estratégia organizacional é que este artigo pretende contribuir. Na seqüência, elabora-se resgate de alguns elementos institucionalistas como recurso de entendimento das organizações e, em seguida, busca-se explorar as possibilidades que aquela teoria oferece para a compreensão da estratégia.

\section{A Teoria Institucional em Organizações: Um Resumo de Vertentes}

No campo da teoria organizacional, a teoria institucional representa alternativa à concepção de ação social predominante há algumas décadas, basicamente aquela de que toda a decisão pode ser dirigida por critérios racionais de escolha. Na perspectiva que aqui chamamos de racionalista, pressupõe-se que o decisor pode ser guiado em suas escolhas apenas por seus próprios interesses, formados consciente e autonomamente, e por visão clara e objetiva das alternativas de 
ação que estão ao seu alcance, além das suas conseqüências. Em termos organizacionais o racionalismo correspondeu sempre à expectativa de superação do irracional pela ciência positiva, “o triunfo da ciência sobre a política, bem como a vitória da ordem e do progresso coletivos, concebidos racionalmente acima da recalcitrância e irracionalidades humanas” (Reed, 1998, p.61). As organizações foram assim compreendidas como instrumentos técnicos, conscientemente planejados para fins específicos.

Entretanto, no fluxo das correntes interpretacionistas de teoria social, a noção de organização começou também a ser alterada, tomando impulso uma concepção de organização enquanto fenômeno socialmente construído, produto não somente das ações humanas intencionais e planejadas, mas também de suas interações culturais e políticas e de processos cognitivos e simbólicos, enfim de toda uma gama de processos sociais não racionais, pelo menos no sentido apenas econômico.

No âmbito dessas novas interpretações, a teoria institucional enfoca a natureza objetivada e taken for granted das organizações e do ambiente organizacional (Meyer e Rowan, 1977; DiMaggio e Powell, 1991). Ao contrário da noção racionalista de ação, na perspectiva institucional ela é compreendida como "representação [enactment] de amplos 'scripts' institucionais mais do que uma questão de escolha, motivação e propósito interna e autonomamente gerados" (Meyer, Boli e Thomas, 1994, p.10).

Essa é uma visão da questão institucional que de fato predomina na teoria organizacional, mas que não é única. As organizações são também analisadas, numa perspectiva institucionalista, por outras áreas do conhecimento, compondose explicações diferentes e divergentes quanto aos significados de instituição e do processo de institucionalização.

Uma dessas áreas é a própria Economia, fonte de várias contribuições para a análise organizacional que, geralmente, são agrupadas sob o nome de economia institucional, além da influência tradicional, a partir do modelo de escolha racional, como já se observou. Williamson (1991), resumindo algumas dessas contribuições, afirma que, na perspectiva de historiadores econômicos, o foco recai sobre amplos papéis institucionais desempenhados por consumidores, leis e políticas no jogo econômico, enquanto para economistas da perspectiva dos custos de transação o foco recai sobre "a eficácia comparativa com que formas genéricas de governança - mercados, híbridos e hierarquias - afetam os custos de transação” (Williamson, 1991, p.269).

Para um dos mais importantes economistas institucionais, as instituições podem ser entendidas como mecanismos ou instrumentos para estruturar a interação 
humana (North, 1991). Sua função principal é, então, diminuir incertezas que dificultam o relacionamento e a ação social. Nesse sentido, elas continuam sendo percebidas como produto racional e intencional, mas sempre limitadamente racionais; em última análise, permitem que os agentes operem estrategicamente.

Percebe-se nessa perspectiva que instituição se refere a padrões concretos, exteriores às organizações, pelo menos individualmente, isto é, elementos ambientais formais e com força coercitiva, como formas consideradas legítimas de governança ou mesmo como sistemas de leis e regras. Como a caracteriza Scott (1995), essa perspectiva institucional está baseada em pressuposto realista, quanto à natureza do social, e em visão das instituições enquanto sistemas regulativos, intencionalmente projetados. Tais instituições possuem, portanto, papel positivo na sociedade, uma vez que possibilitam a ação estratégica.

Um modo alternativo de entendimento desenvolveu-se dentro da assim chamada Sociologia Organizacional, principalmente a partir dos estudos de Philip Selznick. Em tal perspectiva, a força institucional é sobretudo normativa, o que marca o afastamento mais acentuado, relativamente à perspectiva realista anteriormente descrita, da visão de agente racional. O vínculo em torno das ações sociais institucionalizadas é visto como predominantemente cultural, o que se depreende da concepção de institucionalização como atribuição de valor a determinadas estruturas, processos ou comportamentos, quando deixam de ser vistos como respostas meramente técnicas a problemas operacionais (Selznick, 1966; DiMaggio e Powell, 1983).

A importância dessa perspectiva para a teoria organizacional se encontra no fato de que os estudos de Philip Selznick são freqüentemente reconhecidos como estando entre os primeiros esforços relevantes para a formalização de uma análise institucional em organizações (Fligstein, 2001; Scott, 2001). No seu estudo sobre a Tennessee Valley Authority (TVA), Selznick (1966, p.20) afirma: "para se estabelecer, ela [uma organização] não pode depender somente ou mesmo primariamente do apoio difuso de elementos não diretamente envolvidos em seu trabalho; sua liderança administrativa deve encontrar apoio entre as instituições locais e desenvolver relações de trabalho bem ajustadas com elas [...]. Em resumo [...] deve procurar algum tipo de equilíbrio com o ambiente no qual ela existe”.

Na sua abordagem, institucionalização corresponde ao processo pelo qual estruturas se tornam "impregnadas com valores para além dos requisitos técnicos da tarefa” (Selznick, 1957, p.17). Tal perspectiva consiste em ver nas instituições e processos organizacionais institucionalizados exemplos do caráter reativo dos sistemas sociais a seus contextos ambientais (Scott, 1992). Ao mesmo tempo, porém, Selznick (1948) ressalta que tal adaptabilidade tem sempre como 
parâmetro principal a manutenção da integridade do próprio sistema ou a continuidade de sua existência, e está baseada em características e comprometimentos dos seus participantes. Ainda que autores como Scott (1992) apontem tal perspectiva como contingencialista, baseada na concepção de organizações enquanto sistemas abertos, o próprio Selznick (1996) chama atenção para o fato de que os processos cognitivos que interferem na adaptação ao ambiente - foco principal do novo institucionalismo em organizações - não estão ausentes da perspectiva institucional, ainda que não seja a sua vertente essencial. Há em Selznick (1957, p. 4), tanto quanto no novo institucionalismo, o reconhecimento de lógica interna das organizações, relevante para o processo de adaptação, como se depreende da discussão sobre o papel da liderança organizacional: "nenhum processo social pode ser entendido, salvo quando é localizado no comportamento de indivíduos, e especialmente em suas percepções de si próprios e dos outros. O problema está em ligar a perspectiva mais ampla com a mais limitada, ver como a mudança institucional é produzida por interação dos indivíduos e para eles delineada nas situações do dia-a-dia”.

Nesse sentido parece bastante apropriado reconhecer em Selznick as origens de importantes aspectos da abordagem institucional em organizações, não somente nesta perspectiva culturalista ou normativa, como também na perspectiva cognitivista - o novo institucionalismo - e até mesmo nos estudos mais recentes que, como se pretende demonstrar adiante, se caracterizam pela tentativa de conciliação das várias abordagens e que devem ter recebido importante influência e impulso com a publicação do artigo de 1996, em que o autor busca resgatar elementos implícitos em sua obra. Mesmo assim pode-se reconhecer na perspectiva normativa de análise institucional a tendência em considerar o papel das instituições como limitantes da possibilidade de ação estratégica.

Com a crescente visibilidade de teorias sociais de natureza interpretativa, principalmente fenomenológicas, a teoria institucional passou a contar, no final da década de 70, com tendência microssociológica, que enfatiza aspectos cognitivos como intermediários entre as pressões contingentes e as respostas organizacionais (Zucker, 1977). Tal foco não era de todo inédito, como recorda Selznick (1996), porém constitui a ênfase principal e um dos pontos centrais do movimento denominado de novo ou neo-institucionalismo. $\mathrm{O}$ foco de análise do processo de institucionalização deixou de ser o ambiente e passou a ser a própria organização (Zucker, 1987). No caso das pressões legais e normativas externas à organização, elas passaram a ser interpretadas como "mitos racionalizados" (Meyer e Rowan, 1977), isto é, padrões objetivados, "sustentados por crenças que não podem ser objetivamente testadas: são verdadeiras porque se acredita nelas” (Scott, 1992). 
De uma perspectiva apenas cognitiva, instituições passaram a ser definidas como sistemas de conhecimento (Scott, 1995); a institucionalização passou a ser entendida, seguindo a definição do ensaio que talvez seja a mais relevante influência nessa perspectiva, como difusão de ações e significados (Berger e Luckmann, 1997).

O novo institucionalismo, assim, fez voltar o foco da teoria institucional em organizações para o fenômeno da difusão de estruturas e comportamentos (DiMaggio e Powell, 1983), como respostas a incertezas em face da realidade complexa. Um dos pressupostos centrais dessa perspectiva é o de que a realidade é socialmente definida e construída, na medida em que os agentes sociais interagem e definem para si, por processos pouco conscientes ou intencionais, o significado do mundo circundante. As instituições são compreendidas como definidoras de nossa visão de mundo e, com isso, importantes influenciadoras do comportamento social.

Algumas divergências também emergiram dessa perspectiva. Uma delas refere-se à natureza do processo de institucionalização e às suas conseqüências. Zucker (1977), em perspectiva que talvez pudesse ser caracterizada como purista no tocante ao viés microssociológico e ao foco cognitivista do novo institucionalismo, defende que toda difusão institucional implica difusão de significados semelhantes, no que segue a definição de Berger e Luckmann (1997).

A perspectiva etnometodológica da proposta de Zucker (1977) contrapõe principalmente a noção defendida por Meyer e Rowan (1977), no sentido de que, apesar de estruturas serem institucionalizadas, elas podem não ser vinculadas ao comportamento resultante. A noção de decoupling, importante na visão institucional de Meyer e Rowan (1977), representa uma definição específica deles para ação social (afinal, há sempre um significado específico e importante no próprio ato de adotar formalmente uma estrutura social e não agir em conformidade a ela!) e parece apontar para a multiplicidade paradigmática subjacente ao seu texto, para além do purismo metodológico pretendido por Zucker (1977).

Assim, o novo institucionalismo apresenta dois rumos: um predominantemente cognitivista, que busca revelar no processo de institucionalização a tendência à repetição de significados sociais, e outro que admite a possibilidade de que instituições adquiram também aspecto formal, crescentemente externo e desconectado de qualquer significado original. Parece possível reconhecer que a perspectiva predominantemente cognitivista de institucionalização passou a admitir as instituições como determinantes da ação (comportamento e 
significado), enquanto a perspectiva intermediária manteve ainda entendimento mais próximo ao de Selznick no tocante ao papel social das estruturas e processos institucionalizados.

Já na década de 90 a perspectiva institucionalista em organizações caminhou para uma abordagem mais abrangente que, reconhecendo a centralidade dos processos cognitivos, também enfatiza a importância dos padrões socialmente construídos, que adquirem caráter objetivado em amplos sistemas sociais e podem passar a exercer certa força coercitiva ou de homogeneização sobre as organizações (DiMaggio e Powell, 1991; Scott, 1995).

Scott (1995), por exemplo, admite que a teoria institucional privilegia uma perspectiva cognitiva e simbólica. Assim, seguindo a tradição weberiana, o autor admite que a noção de ação social subjacente à teoria institucional pode ser assim resumida: "ação é vista como social apenas na extensão em que os atores vinculam algum significado a ela. Estímulos ambientais devem ser cognitivamente processados pelos atores, interpretados pelos indivíduos por meio do emprego de sistemas simbólicos socialmente constituídos, antes que eles possam responder aos estímulos, realizando algum tipo de ação” (Scott, 1995, p.xiii). Instituições são, portanto, definidas por Scott (1995, p.xiii) como "estruturas e atividades cognitivas, normativas e regulativas que provêem estabilidade e significado ao comportamento social”.

Essa vertente institucionalista é também decorrente da fenomenologia e da etnometodologia. Apesar disso, não se limita à explicação da repetição de ações e significados sociais, nem nega a realidade e a força coercitiva dos padrões regulativos e normativos, ainda que reconheça sua natureza de realidade socialmente ou intersubjetivamente construída, como parecem apontar alguns estudos mais recentes (por exemplo, Greenwood e Hinings, 1996; Roberts e Greenwood, 1997; Dirsmith, Thimoty e Gupta, 2000; Lawrence, Winn e Jennings, 2001). Assim como na Economia uma perspectiva institucional se constituiu para incorporar, dentro da lógica da agência estratégica, a noção de limites sociais da racionalidade, essa vertente mais recente do institucionalismo em organizações parece ter como ponto central a busca por conciliar as noções de institucionalização e de agência estratégica.

Como já se afirmou em outro momento deste artigo, esta também não é vertente totalmente inédita na teoria organizacional. Weick (1969) e Orton e Weick (1990), por exemplo, reconhecem uma dupla lógica dos sistemas sociais, na medida em que se conectam com o ambiente circundante e mantêm, simultaneamente, necessária distinção ou identidade própria em relação a outros sistemas e ao próprio ambiente; para Weick (1969) as organizações são sistemas 
simultaneamente abertos e fechados. Ver também Luhmann (1995). A noção de sistemas frouxamente conectados (March e Simon, 1972; March e Olsen, 1976; Weick, 1976) deriva dessa concepção neo-funcionalista e parece ter ressonância em várias das tentativas mais recentes de revisão da teoria neo-institucional em organizações.

Uma importante contribuição para essa vertente deu-se com a proposição de Oliver (1991) de fazer convergir explicações derivadas da teoria institucional e da teoria da dependência de recursos, para configurar diferentes padrões de resposta estratégica ao ambiente institucional. Nesta perspectiva, parece implícita a idéia de plano sistêmico de institucionalização, seguindo a sugestão de Meyer e Rowan (1977). Outros esforços mais recentes vão também seguir essa linha, como, por exemplo, os de Roberts e Greenwood (1997), que elaboram estrutura explicativa para a busca de eficiência em organizações, eficiência entendida por eles como limitada por fatores cognitivos e institucionais. Os fatores institucionais são entendidos como fatores pré e pós-conscientes, de acordo com o seu efeito nos agentes organizacionais, isto é, resultando em supressão ou não da capacidade de se perceber como agente auto-interessado. Nesse estudo, como também no estudo de Oliver (1991), defende-se a possibilidade de ação consciente e até divergente em relação a padrões institucionalizados. Em estudos como os de Dirsmith, Thimoty e Gupta (2000) e Westphal e Zajac (2001), tal possibilidade é explicitamente desenvolvida.

Mesmo a perspectiva que se pretende apenas etnográfica parece ter sofrido influência dessa busca por conciliação de padrões institucionais e estratégicos. O estudo de Meyerson (1994), por exemplo, explora as formas pelas quais padrões culturais internos às organizações podem refletir e reforçar os padrões institucionalizados. A autora também admite a existência de "sistemas institucionais”, apesar de sua perspectiva metodológica declaradamente etnográfica.

Em resumo, nessa última vertente do institucionalismo em organizações buscase trazer para a perspectiva institucional a noção de agência estratégica, de uma forma ou de outra, seja reconhecendo uma lógica individual ou uma lógica sistêmica de interação dos agentes com o seu ambiente institucional. Constituise em vertente promissora, em termos de superação de uma das principais limitações da teoria institucional em organizações (Beckert, 1999), além do fato de tornar especialmente interessante a possibilidade de constituição de uma perspectiva institucional de análise do pensamento estratégico. 
Contribuições para uma Abordagem Institucional da Estratégia em Organizações

Uma perspectiva ambientalista, do tipo da economia institucional, permite ver que o processo estratégico vai além da fronteira das organizações, implicando a idéia de construção intencional de instituições que são a estrutura social dentro da qual se dá a ação estratégica de empresas e empreendedores. O papel do estrategista, nesta perspectiva, envolve também empreender instituições (idéia introduzida por DiMaggio [1988] e que, portanto, não tem relação apenas com a economia institucional), isto é, influenciar os padrões formais de relação social que organizam as interações entre e dentro das organizações e que, assim, dão relativa estabilidade ao comportamento social e permitem a diminuição das incertezas. Nessa perspectiva parece possível compreender melhor os jogos de poder entre influentes atores sociais como uma das importantes fontes de mudança institucional e também as limitações que se impõem sobre agentes de menor influência, na medida em que esses se tornam, em face daquelas instituições, praticamente apenas agentes reativos.

Essa perspectiva é voluntarista no concernente à relação organização-ambiente, porque compreende o ambiente como produto da ação interessada e racional, e também no que diz respeito às relações entre importantes e influentes agentes sociais: estratégia pode ser entendida como o esforço para constituição de uma ordem limitadamente intencional que permita maximizar a liberdade dos agentes pela busca da realização de interesses. Expande-se o papel do estrategista e o campo de atuação de agentes prospectores, uma vez que qualquer prospecção passa a considerar também contradições institucionais como oportunidades de sua reconfiguração (Seo e Creed, 2002). Passa a ter sentido a idéia de empreendedores institucionais, isto é, "agentes que têm interesses em estruturas institucionais específicas e que detêm recursos que podem ser aplicados para influenciar as regras institucionalizadas, tanto pelo comprometimento daqueles recursos para dar apoio às instituições existentes quanto pelo seu uso para a criação de novas instituições” (Beckert, 1999, p.781).

A estratégia organizacional, nessa perspectiva, passa assim a incorporar não somente o planejamento interno da organização, mas também as relações interorganizacionais, melhor dito, interinstitucionais, como forma de promover as condições futuras de existência da organização. Como bem se percebe, o impacto de uma perspectiva institucional dessa natureza não se restringe à noção de empreendedorismo, mas implica também a expansão das visões tradicionais, quanto a planejamento e posicionamento estratégico, além das discussões sobre poder subjacente à decisão estratégica. Porém, como já se destacou, essa 
perspectiva é bastante otimista quanto ao papel das instituições e também voluntarista em relação à própria natureza delas, o que é questionado pela perspectiva sociológica que marca o institucionalismo em organizações, nas suas várias vertentes.

Na vertente normativista da perspectiva institucional em organizações, o papel do estrategista está aquém do planejamento dos padrões institucionais. Neste caso, o papel da liderança organizacional é o de perceber as demandas ambientais e conformar a estrutura social da organização, de modo a incorporar aquelas demandas ou pressões. Essa incorporação institucional (Selznick, 1957) deve atingir a definição de missão, dos propósitos da organização, tanto quanto os papéis nela desempenhados pelos vários agentes. É por meio dessa incorporação que irão ser constituídas as feições distintivas da própria organização, sendo portanto esse processo essencial para a sobrevivência organizacional.

Nessa perspectiva a estratégia pode ser entendida como essencialmente cultural e política, voltada à construção da adequação interna da organização às pressões contingenciais, construção essa que se dá pela difusão interna dos valores socialmente predominantes: "a liderança cria e molda a incorporação organizacional - no pensamento, sentimento e hábito - das premissas de valor. A liderança reconcilia os esforços internos com as pressões ambientais” (Selznick, 1957, p.62). Apresenta-se, assim, como resposta tanto operacional quanto simbólica, isto é, tanto relacionada às demandas técnicas e produtivas quanto à necessidade de demonstrar aceitação dos valores sociais predominantes.

Na verdade, essa vertente conduz à idéia de que a própria resposta operacional deverá ser moldada em conformidade com os valores sociais predominantes, sob pena de perda de legitimidade por parte da organização. Considerar essa vertente institucional na análise das estratégias implica, assim, claro confronto com as perspectivas de planejamento racional e baseado apenas na otimização de recursos, ou eficiência, algo tão caro à Economia de Empresa e às primeiras perspectivas estratégicas, porque o que é tecnicamente ótimo pode não coincidir com padrões sociais e sua adoção levaria à circunstância de perda de legitimidade e de poder por parte da estrutura social da organização. De igual modo, opções com menor grau de eficiência técnica podem ser mais socialmente aceitas e implementadas a despeito dos resultados operacionais. Essa vertente institucional permite reconhecer as organizações como agentes sociais essencialmente políticos e as suas estratégias como produtos dessa característica ou, pelo menos, como processos nos quais ela irá manifestar-se de forma acentuada.

O neo-institucionalismo vem agregar o aspecto cognitivo como fator relevante na análise das estruturas organizacionais institucionalizadas. Ainda que se haja 
passado a dar mais ênfase aos processos de reprodução das estruturas sociais, não se abandonou completamente a idéia de ação simbólica como decorrente da confrontação das organizações com padrões sociais predominantes, ao menos em algumas de suas vertentes. Tal reprodução segue a intenção de se demonstrar para agentes externos e mesmo para stakeholders importantes a seriedade das intenções da organização, agora com o destaque para a sugestão de que o esforço por mapear as estruturas e processos que podem ser considerados socialmente relevantes demanda percepção, seleção e interpretação dos agentes organizacionais.

Nessa perspectiva as estratégias adotadas nas organizações podem ser compreendidas como decorrentes de padrões institucionalizados no ambiente organizacional, que podem ser difundidos por mecanismos coercitivos, normativos ou miméticos (DiMaggio e Powell, 1991). De qualquer modo e principalmente na vertente cognitivista do neo-institucionalismo, uma estratégia pode ser entendida como institucionalizada quando assumir caráter de fato social, isto é, quando sua adoção, em forma e significado, for considerada a alternativa normal ou inescapável, em nível de internalização bastante alto até para dificultar a articulação explícita das razões de sua adoção (Zucker, 1983). Como destaca Beckert (1999), tal vertente admite a noção de agente culturalmente determinado, o que, em termos de análise estratégica, lança sério questionamento quanto ao papel ou autonomia do estrategista em relação ao comportamento real das organizações. Como também sugere Beckert (1999), essa vertente dificulta qualquer idéia de agência em face de padrões institucionalizados, criando ruptura entre teoria institucional e agência estratégica como possibilidades simultâneas.

Ela não deixa de oferecer, entretanto, importantes possibilidades para a compreensão da natureza das estratégias e do pensamento estratégico. Por exemplo, no contexto brasileiro, são vários os estudos que apontam para os limites cognitivos que se impõem à elaboração estratégica nas organizações (Machadoda-Silva e Fonseca, 1999; Machado-da-Silva, Fonseca e Fernandes, 1999; Gimenez, 2000, por exemplo). Uma perspectiva institucional vai agregar a tais limites o fato de que as opções com que se deparam os agentes organizacionais têm natureza interpretativa, sendo que a interpretação que fazem em face da complexidade da realidade, é processo baseado, em grande medida, em aspectos como valores e crenças, que são socialmente construídos a partir de suas interações sociais.

Assim, mesmo quando pensam estar seguindo processo lógico e racional de decisão, os agentes organizacionais poderão estar na verdade apenas seguindo padrões percebidos como racionais, dentro dos seus limites cognitivos pessoais e dos limites impostos pelo ambiente institucional como respostas apropriadas 
ou únicas para determinado problema. Nessa perspectiva a própria necessidade de tornar racional a elaboração de estratégias decorre de um padrão socialmente válido, que legitima tal necessidade e a faz ser percebida como a melhor forma de agir em relação à realidade. De outro modo, o processo racional de decisão nada mais é do que uma ordenação da realidade, para seguir a noção de Weick (1969), uma entre outras formas possíveis, embora não tão fortemente legitimadas no contexto industrial moderno.

Numa vertente predominantemente cognitivista entende-se o estrategista como imerso na estrutura social circundante e relativamente inconsciente quanto a ela e quanto à sua influência sobre suas próprias opções e procedimentos. Elaboração e escolha estratégica passam a seguir os padrões institucionalizados no ambiente, sendo que o estrategista continua a acreditar que está decidindo e agindo seguindo apenas princípios racionais, em função de objetivos de otimização técnica. É nesse sentido que Holm (1995) chama atenção para o fato de que aqueles fenômenos, situações ou práticas que se apresentam como técnicas, naturais e auto-evidentes são, possivelmente, os que mais estão institucionalizados, exatamente porque permanecem taken for granted, isto é, não são analisados ou sequer percebidos enquanto construções sociais.

Desse modo, em face de qualquer padrão institucionalizado, os agentes irão sempre agir imbuídos de boa intenção, por assim dizer. Em decorrência, quando se começa a perceber incoerências entre os padrões institucionalizados e os resultados obtidos, ocorre a tendência de pôr sob suspeita tais padrões, originandose daí o processo de mudança institucional e organizacional. Como se pode perceber, coerência e ausência de contradição são considerados os padrões normais nessa vertente, o que tem importantes decorrências para a análise estratégica em organizações, como se busca explorar a seguir.

Já numa vertente do neo-institucionalismo como a de Meyer e Rowan (1991), parece possível afirmar que a estratégia pode ser entendida como tendo decorrências tanto no âmbito das estruturas formais da organização quanto no âmbito informal. Analisar apenas as estratégias formais ou declaradas de uma organização (os planos, por exemplo) seria questionável, uma vez que tais estratégias declaradas podem constituir meros recursos para evitar ou minimizar a avaliação dos procedimentos concretos e das ações reais por parte de agentes externos.

Uma vertente como essa lança luz sobre a necessidade de se considerar na análise estratégica não somente os aspectos formais e predeterminados, mas principalmente os aspectos emergentes e contingenciais que surgem no cotidiano da organização, como contexto importante de elaboração de estratégias. Por outro 
lado, analisar apenas os aspectos informais, decorrentes da ação local e imediata, seria negar a possibilidade de institucionalização num plano sistêmico, mais amplo que o grupo que interage diretamente ou mesmo a organização.

Como destaca Selznick (1996), essa vertente relaciona-se fortemente com a idéia de organizações enquanto sistemas loosely coupled. Espera-se que na medida em que a análise estratégica avance para considerar a dinâmica informal e cotidiana das respostas organizacionais, se torne possível perceber que toda a noção de clareza e coesão sugeridas pelas estratégias formais venha a ruir, compondo-se um quadro em que a organização seja mais adequadamente entendida como conjunto de estruturas, procedimentos e agentes pouco relacionados entre si - às vezes mais, às vezes menos conectados - cuja coordenação burocrática e controle central sejam pouco mais do que ilusão. A grande estratégia central, coordenadora dos interesses e esforços de todos os agentes organizacionais, poderia ser assim entendida como mais um mito da organização moderna e da sociedade industrial, estruturado por, e estruturante de, ritos racionalizados, cuja função seria difundir satisfação, boa fé e confiança (Selznick, 1996), transmitindo a mensagem de que 'as coisas caminham como deveriam caminhar'.

Ao contrário, porém, do julgamento negativo que se faz em relação a tais processos em vertentes cognitivistas da teoria neo-institucional, Selznick (1996) reconhece neles algum valor moral e criativo, na medida em que eles podem ser relacionados com a natureza parcialmente autônoma dos sistemas sociais. Da mesma forma que na perspectiva de Selznick, o institucionalismo de Meyer e Rowan permite expandir a noção de poder subjacente à configuração de estratégias organizacionais, no sentido de que tal poder não somente é importante na análise interna, como também e até principalmente na análise da estratégia como meio de intermediação de pressões ambientais, principalmente normativas, com dinâmicas internas, operacionais ou mesmo políticas. Tal vertente ressalta o conflito, a divergência, a diferença e até a incoerência como normais, ao contrário das perspectivas racionalistas de estratégia organizacional; ao contrário também da vertente predominantemente cognitivista da teoria institucional em organizações, que tende a ressaltar a lógica, no caso das primeiras, e a semelhança de estruturas e comportamentos, na segunda, como aspectos normais da realidade.

Dessa tendência é que parece emergir a vertente mais atual do institucionalismo em organizações que, como já se explorou neste texto, busca conciliar padrões institucionalizados com ação estratégica. Tais estudos compõem um quadro muito menos homogêneo que o das demais vertentes, até por conta da intenção, geralmente explícita, de seus autores por construir sínteses entre teorias de natureza racionalista e a teoria institucional; mas parecem sugerir, de forma geral, 
que a existência de padrões sociais institucionalizados é tanto o produto quanto a condição para a ação estratégica.

Nessa vertente busca-se explicitar os mecanismos pelos quais não somente os padrões institucionalizados afetam a configuração das estratégias, mas também os mecanismos pelos quais agentes organizacionais, por intermédio de uma série de fatores - como interesses, em Beckert (1999), diferentes percepções, em Roberts e Greenwood (1997) e Westphal e Zajac (2001) ou mesmo condições organizacionais, como em Meyerson (1994) e em Lounsbury (2001) - elaboram diferentes formas de responder àqueles padrões. Constituise, portanto, como concepção central da vertente a idéia de que os processos de institucionalização e de ação estratégica podem ser interpretados como possuindo uma lógica complementar ou circular, de mútuo condicionamento, reforço e mudança (sugere-se ver também a interessante exploração da natureza construtivista da perspectiva neo-institucional e sua relação com a análise estratégica em Vasconcelos [2002]).

Essa vertente vai muito além da simples sugestão de que as organizações se adaptam a ambientes institucionais. Ela sugere que há um processo de mútua construção e reconstrução entre ambiente e organizações, sendo a estratégia importante elemento, não somente de intermediação como também de construção do ambiente e dos agentes envolvidos. Sugere, ademais, que, em face de padrões institucionalizados em elevado grau no plano sistêmico, os agentes organizacionais podem ver-se na circunstância de revisão do significado de seus procedimentos instrumentais e estratégias adotadas (Dirsmith, Thimoty e Gupta, 2000; Vasconcelos, 2002), que podem então assumir papel predominantemente simbólico, (tornando-se a organização, em conseqüência, um conjunto de estratégias e procedimentos pouco conectados entre si e com o ambiente) ou pelo menos ser afetados na forma como são percebidos pelos agentes.

De modo geral, essa vertente sugere que estratégias podem ser mais bem compreendidas como representando sempre a relação frouxamente conectada entre organização e ambiente, e a elaboração dessas estratégias como processo passivo e ativo, nunca apenas um ou outro, na resposta às pressões institucionais. Nesses termos ela sugere uma perspectiva neo-funcionalista de teoria organizacional ${ }^{(2)}$, pois está baseada implícita ou, em alguns casos, como em Weick (1969), explicitamente, na concepção de sistemas simultaneamente abertos e fechados. 


\section{Considerações Finals}

A convergência entre teoria institucional em organizações e pensamento estratégico indica superação de limitações nessas duas perspectivas. No tocante ao pensamento estratégico, indica a superação da predominância do tradicional modelo de escolha ou adaptação racional em relação à explicação da configuração das estratégias organizacionais. No tocante à teoria institucional, indica o seu enriquecimento em direção à incorporação de visão menos socialmente determinista em relação à natureza dos indivíduos e dos sistemas sociais, visão que indica a superação de um dos seus aspectos mais criticados: "a maior crítica quanto à teoria institucional tem sido em relação aos seus pressupostos de passividade organizacional e sua falha em permitir algum espaço para o comportamento estratégico e o exercício da influência em sua concepção de institucionalização” (Oliver, 1991).

No geral, ocorre nos estudos mais recentes o que Oliver (1991) preconiza como condição para que a teoria institucional se torne significativa como via explicativa pelo menos de alguns aspectos da estratégia, isto é, a organização deixa de ser vista apenas como se conformando ou resistindo às pressões de seu contexto ambiental. Parece haver hoje crescente consenso de que esses processos são simultâneos, ocorrendo de diversas formas, seja pela separação entre manifestações simbólicas e manifestações instrumentais dos processos organizacionais (Westphal e Zajac, 2001), seja enquanto processo dialético (Seo e Creed, 2002), ou mesmo como processo de interdependência da instituição com a agência estratégica (Beckert, 1999).

Uma perspectiva institucionalista em estratégia incorporaria, conforme toda a discussão aqui apresentada, elementos ambientais, culturais, cognitivos e sistêmicos para entender o processo de formação estratégica. A configuração de estratégias, em decorrência, poderia ser entendida como resultante da ação de indivíduos e sistemas socialmente imersos, que apesar disso não perdem, pelo menos totalmente, seu caráter distinto em relação a seu contexto.

De qualquer modo, tal visão significa ruptura, questionamento ou pelo menos enriquecimento, dependendo da vertente adotada, em relação às explicações de cunho racionalista. Ela significa também a superação de uma série de mitos gerencialistas que predominaram por muito tempo na literatura administrativa e organizacional e que sugeriam a figura do estrategista como a de um semideus, capaz de observar a realidade em suas inúmeras interrelações e planejar autonomamente ações condizentes e coerentes, interferindo naquela realidade para a corrigir. A idéia de que estrategistas sejam agentes absolutamente 
independentes, racionais e onipotentes em face de uma realidade organizada e coerente por natureza, é mais um mito moderno que não se sustenta em face de uma perspectiva estratégica institucionalista.

Por fim, a possibilidade de síntese entre teoria institucional e perspectiva estratégica parece viabilizar abordagem organizacional que vai além da visão caricatural, como as define Oliver (1991), das perspectivas puristas quanto à institucionalização e a agência estratégica, diminuindo o reducionismo inocente, por vezes intencionalmente simplista, que dificulta avanços tanto teóricos quanto operativos no entendimento do comportamento das organizações e dos indivíduos dentro delas.

\section{Notas}

${ }^{1}$ Sobre este aspecto, agradecemos ao Professor Dr. Clóvis L. Machado-da-Silva e à Professora Dra. Valéria Silva da Fonseca a sua contribuição, durante o I Encontro de Estudos em Estratégia, ao nos chamar a atenção para o fato de que a teoria institucional não abandona o pressuposto de racionalidade como fator explicativo importante, mas está baseada principalmente no pressuposto de racionalidade limitada. Tal crítica nos permitiu identificar uma imprecisão no artigo, que buscamos corrigir, ressaltando, ao invés do termo genérico racionalidade, a idéia mais específica de escolha racional ou de adaptação racional, querendo com isso dar destaque ao fato de que a teoria institucional em organizações flexibiliza a noção mais estrita de racionalidade que influencia fortemente a tradição dos estudos em estratégia. Agradecemos ainda a um revisor anônimo desta revista, que também nos fez semelhante alerta.

${ }^{2}$ Luhmann (1989) apresenta o neofuncionalismo como a perspectiva que admite a crescente diferenciação funcional como característica moderna, à semelhança de Parsons; mas vai além da teoria parsoniana, acrescentando a noção de que os sistemas sociais adquirem crescentemente uma lógica de auto-referência, isto é, a determinação interna por meio de codificação, específica a cada tipo de sistema social, o que implica reconhecer neles sistemas simultaneamente abertos e fechados, sendo que o contato com o ambiente se dá por meio de interpenetrações de sistema e ambiente. Por meio dos conceitos de autonomia (base do fechamento sistêmico) e interpenetração (base da abertura das fronteiras do sistema), define-se o sistema social como se comunicando com o ambiente e, ao mesmo tempo e necessariamente, mantendo sua identidade. "Fechamento organizacional não significa que um sistema não pode ser afetado de nenhuma forma por seu ambiente. Mas significa que, como uma unidade autônoma [...] ele pode reagir ao seu ambiente apenas de acordo com seu próprio modo de operação, o modo de operação peculiar a ele” (Bednarz Jr., 1989, p. xii-xiii).

Artigo recebido em 21.07.2003. Aprovado em 04.12.2003. 


\section{REFERÊNCIAS BIBLIOGRÁFICAS}

ACKOFF, R.

Beyond prediction and preparation. Journal of Management Studies, v. 20, n. 1, p. 59-69, 1983.

ANDREWS, K.

Replaying the board's role in formulating strategy. Harvard Business Review, v. 54, n. 3, p. 1827, 1981.

\section{BECKERT, J.}

Agency, entrepreneurs, and institutional change: the role of strategic choice and institutionalized practices in organizations. Organization Studies, v. 20, n. 5, p. 777-799, 1999.

\section{BEDNARZ JR, J.}

Translator's introduction. In: LUHMANN, N. Ecological communication. Chicago: The University of Chicago Press, 1989. p. vii-xvi.

BERGER, P.;

LUCKMANN, T.

A construção social da realidade. 14. ed. Petrópolis: Vozes, 1997.

DIMAGGIO, P.

Interest and agency in institutional theory. In: ZUCKER, L. (Ed.). Institutional patterns and organizations: culture and environment. Cambridge, MA: Ballinger, 1988.
DIMAGGIO, P.;

POWELL, W.

The iron cage revisited: institutional isomorphism and collective rationality in organizational fields. American Sociological Review, v. 48, p. 147-160, 1983.

The new institutionalism in organizational analysis. Chicago: The University of Chicago Press, 1991.

DIRSMITH, M.;

TIMOTHY, F.;

GUPTA, P.

Institutional pressures and symbolic displays in a GAO context. Organization Studies, v. 21, n. 3, p. 515-537, 2000.

FLIGSTEIN, N.

Organizations: theoretical debates and the scope of organizational theory. Berkeley: Department of Sociology/ University of California, 2001.

FONSECA, V. S. DA;

MACHADO-DA-SILVA, C. L. Indivíduo, organização e ambiente: bases para a conversação entre três perspectivas de estudo da estratégia em organizações. In: ENCONTRO ANUAL DA ANPAD, 25., 2001, Campinas. Anais ... Rio de Janeiro: ANPAD, 2001. 1 CD-ROM.

GIMENEZ, F. A.

$O$ estrategista na pequena empresa. Maringá: [s.n.], 2000. 
GREENWOOD, R.;

HININGS, C. R.

Understanding radical organizational change: bringing together the old and the new institutionalism. Academy of Management Review, v. 21, n. 4, p. 1022-1054, 1996.

HOLM, P.

The dynamics of institutionalization: transformation processes in Norwegian fisheries. Administrative Science Quarterly, v. 40, p. 398-422, 1995.

\section{LAWRENCE, T.;}

WINN, M.;

JENNINGS, P. D.

The temporal dynamics of institutionalization. Academy of Management Review, v. 26, n. 4, p. 624-644, 2001.

\section{LINDBLON, C.}

The science of muddling through. Public Administration Review, v. 19, p. 78-88, 1959.

\section{LOUNSBURY, M.}

Institutional sources of practice variation: staffing college and university recycling programs. Administrative Science Quarterly, v. 46, p. 29-56, 2001.

\section{LUHMANN, N.}

Ecological communication. Chicago: The University of Chicago Press, 1989.

MACHADO-DA-SILVA, C. L.; FONSECA, V. S. DA.

Competitividade organizacional: conciliando padrões concorrenciais e padrões institucionais. In: VIEIRA, M. M. F.; OLIVEIRA, L. M. B. DE.
(Orgs). Administração contemporânea: perspectivas estratégicas. São Paulo: Atlas, 1999. p. 27-39.

MACHADO-DA-SILVA, C. L.; FONSECA, V. S. DA.; FERNANDES, B.

Mudança e estratégia nas organizações: perspectivas cognitiva e institucional. In: VIEIRA, M. M. F.; OLIVEIRA, L. M. B. DE. (Orgs). Administração contemporânea: perspectivas estratégicas. São Paulo: Atlas, 1999. p. 102-118.

\section{MARCH, J.;}

OLSEN, J.

Ambiguity and choice in or ga n i za ti on s. O s l o : Universitetsforlaget, 1976.

\section{MARCH, J.;}

SIMON, H.

Teoria das organizações. 2. ed. Rio de Janeiro: Fundação Getúlio Vargas, 1972.

\section{MEYER, J.;}

BOLI, J.;

THOMAS, G.

Ontology and rationalization in the Western cultural account. In: SCOTT, W. R.; MEYER, J. Institutional environments and organizations: structural complexity and individualism. London: Sage Publications, 1994. p. 9-27.

\section{MEYER, J.;}

ROWAN, B.

Institutionalized organizations: formal structure as myth and ceremony. American Journal of Sociology, v. 83, n. 2, p. 340-363, 1977. 
MEYERSON, D.

Interpretations of stress in institutions: the cultural production of ambiguity and burnout. Administrative Science Quarterly, v. 39, p. 628-653, 1994.

\section{MILLER, S.; \\ HICKSON, D.; \\ WILSON, D.}

Decision-making in organizations. In: CLEGG, S.; HARDY, C.; NORD, W. (Eds). Handbook of organization studies. London: Sage Publications, 1996. p. 293-312.

MINTZBERG, H.;

AHLSTRAND, B.;

LAMPEL, J.

Safári de estratégia: um roteiro pela selva do planejamento estratégico. Porto Alegre: Bookman, 2000.

NORTH, D.

Institutions. The Journal of Economic Perspectives, v. 5, n. 1, p. 97-112, 1991.

OLIVER, C.

Strategic responses to institutional processes. Academy of Management Review, v. 16, n. 1, p. 145-179, 1991.

ORTON, J. D.;

WEICK, K.

Loosely coupled systems: a reconceptualization. Academy of

Management Review, v. 15, n. 2, p. 203-223, 1990.

\section{REED, M.}

Teorização organizacional: um campo historicamente contestado. In: CLEGG, S.; HARDY, C.; NORD, W.
(Eds.). Handbook de estudos organizacionais. São Paulo: Atlas, 1998. v. 1. p. 61-98.

ROBERTS, P.;

GREENWOOD, R.

Integrating transaction cost and institutional theories: toward a constrained-efficiency framework for understanding organizational design adoption. Academy of Management Review, v. 22, p. 2, p. 346-373, 1997.

SCOTT, W. R.

Organizations: rational, natural, and open systems. 3. ed. Englewood Cliffs, NJ: Prentice Hall, 1992.

Introduction: institutional theory and organizations. In: SCOTT, W. R.; CHRISTENSEN, S. (Eds). The institutional construction of organizations: international and longitudinal studies. London: Sage Publications, 1995. p. xi-xxiii.

Institutions and organizations. 2. ed. London: Sage Publications, 2001.

\section{SELZNICK, P.}

Foundations of the theory of organization. American Sociological Review, v. 13, p. 25-35, 1948.

Leadership in administration. Evanston, IL: Row, Peterson and Company, 1957.

TVA and the grass roots. New York: Harper \& Row, 1966.

Institutionalism "old” and "new". Administrative Science Quarterly, v. 41, p. 270-277, 1996. 
SEO, M.;

CREED, W. E.

Institutional contradictions, praxis, and institutional change: a dialectical perspective. Academy of Management Review, v. 27, n. 2, p. 222-247, 2002.

SIMON, H.

Comportamento administrativo. 2. ed. Rio de Janeiro: Fundação Getúlio Vargas, 1970.

TOLBERT, P.;

ZUCKER, L.

A institucionalização da teoria institucional. In: CLEGG, S.; HARD, C.; NORD, W. (Eds.). Handbook de estudos organizacionais. São Paulo: Atlas, 1998. v. 1. p. 196-219.

\section{VASCONCELOS, F.}

Safári de estratégia, questões bizantinas e a síndrome do ornitorrinco: uma análise empírica dos impactos da diversidade teórica em estratégia empresarial sobre a prática dos processos de tomada de decisão estratégica. In: ENCONTRO ANUAL DA ANPAD, 25., 2001, Campinas. Anais... Rio de Janeiro: ANPAD, 2001. 1 CD-ROM.

WEICK, K.

The social psychology of organizing. Reading, MA: AddisonWesley, 1969.

Educational organizations as loosely coupled systems. Administrative Science Quarterly, v. 21, p. 1-19, 1976.
Making sense of the organization.

Oxford: Blackwell, 2001.

WESTPHAL, J.;

ZAJAC, E.

Decoupling policy from practice: the case of stock repurchases programs. Administrative Science Quarterly, v. 46, p. 202-228, 2001.

WHIPP, R.

Creative deconstruction: strategy and organizations. In: CLEGG, S.; HARDY, C.; NORD, W. (Eds). Handbook of organization studies. London: Sage Publications, 1996. p. 261-275.

WILLIAMSON, O.

Comparative economic organization: the analysis of discrete structural alternatives. Administrative Science Quarterly, v. 36, n. 2, p. 269-296, 1991.

\section{ZUCKER, L.}

The role of institutionalization in cultural persistence. American Sociological Review, v. 42, p. 726743, 1977.

Institutional theories of organization. Annual Review of Sociology, v. 13, p. 443-464, 1987.

The role of institutionalization in cultural persistence. In: DIMAGGIO, P.; POWELL, W. (Eds). The new institutionalism in organizational analysis. Chicago: The University of Chicago Press, 1991. p. 83-107. 